\title{
Estimation of the Number of Excess Hospitalizations Attributed to Sulfur Dioxide in Six Major Cities of Iran
}

\author{
Majid Kermani,, ${ }^{1,2}$ Sevda Fallah Jokandan, ${ }^{2}$ Mina Aghaei, ${ }^{3,4,}$ Farshad Bahrami Asl, ${ }^{5}$ Sima Karimzadeh, ${ }^{6}$ \\ and Mohsen Dowlati ${ }^{1}$ \\ ${ }^{1}$ Research Center for Environmental Health Technology, Iran University of Medical Sciences, Tehran, IR Iran \\ ${ }^{2}$ Environmental Health Engineering Department, School of Public Health, Iran University of Medical Sciences, Tehran, IR Iran \\ ${ }^{3}$ Department of Environmental Health Engineering, School of Public Health, Tehran University of Medical Sciences, Tehran, IR Iran \\ ${ }^{4}$ Center for Air Pollution Research (SAPR), Institute for Environmental Research (IER), Tehran University of Medical Sciences, Tehran, IR Iran \\ ${ }^{5}$ Department of Environmental Health Engineering, School of Public Health, Hamadan University of Medical Sciences, Hamadan, IR Iran \\ ${ }^{6}$ Department of Environmental Health Engineering, School of Public Health, Urmia University of Medical Sciences, Urmia, IR Iran \\ "Corresponding author: Mina Aghaei, Department of Environmental Health Engineering, School of Public Health, Tehran University of Medical Sciences, Tehran, IR Iran, \\ E-mail: Aghaei.mina11@yahoo.com
}

Received 2016 April 25; Revised 2016 August 17; Accepted 2016 August 29.

\begin{abstract}
Background: Air pollution is an important issue and public concern throughout the world. Sulfur dioxide is one of the pollutants that can lead to many adverse effects on human health, animal and plant life.

Objectives: Our study aimed to estimate excess hospitalization cases due to chronic obstructive pulmonary disease (COPD) and acute myocardial infarction (AMI) disease due to short-term exposure to $\mathrm{SO}_{2}$ during years 2011 to 2012, in six major cities of Iran including Tehran, Mashhad, Tabriz, Isfahan, Shiraz and Urmia.

Methods: First, hourly air pollution data related to $\mathrm{SO}_{2}$ were obtained from the department of environmental in six major cities of Iran. Next, required parameters were calculated and imported to AirQ software after data analysis and processing. Finally, output results of the number of excess hospitalizations attributed to $\mathrm{SO}_{2}$ was presented in the form of tables and graphs.

Results: The total cumulative numbers of hospital admissions due to COPD (HA-COPD) were estimated in six Iranian major cities, which were 243 in central relative risk in a year. For hospital admission due to Acute Myocardial Infraction (HA-AMI), the highest impact of SO2 exposure was for Urmia with attributable proportion (AP) of $4.56 \%$, corresponding to 41 excess cases in this city.

Conclusions: Although relative risk per $10 \mu \mathrm{g} / \mathrm{m}^{3}$ is low and sometimes mortality and morbidity attributable to pollutant seems slight because of sensitive and large population exposed to air pollutants, burden of disease associated with air pollution will be great. Therefore, authorities should apply necessary actions and efforts based on comprehensive scientific researches in order to control air pollutants and abate their negative effects on human health.
\end{abstract}

Keywords: Air Pollution, Sulfur Dioxide, Hospital Admission, Iran

\section{Background}

Air pollution is an important issue and public concern throughout the world. It is responsible for many adverse health effects on human health and the environment $(1,2)$. Sulfur dioxide is one of the pollutants that come from combustion of fuels containing sulfur (such as oil, coal, gas and petroleum), refineries and vehicle emissions (3). This pollutant is a severe irritant and reactive gas, which can be absorbed through nose and lower respiratory tract at inhalation exposure (4). Sulfur dioxide causes inflammation, constriction and creates mucus by reducing the diameter of airways (3). At various concentrations of $\mathrm{SO}_{2}$, pollutant has effects on different systems and organs and exposure can lead to a wide range of side effects from bronchospasm to coughing, eye irritation, edema and vascular changes (4, 5).
Sulfur dioxide and particulate matters (PM) are pollutants co-existing in coal-smoke air pollution that account for the main portion of the pollutant burden in many cities of the world (5-7). They can affect the respiratory system because of their synergistic impacts (8). Emission of sulfur dioxide can contribute to the acidification of surface water, crops, forests and ecosystem that can be considered as a cause of deforestation (9). Some epidemiological studies reported that exposure to elevated air pollutants such sulfur dioxide can contribute to an increase in mortality due to respiratory and cardiovascular causes $(10,11)$ and daily hospital admissions due to chronic obstructive pulmonary disease (COPD) $(12,13)$, asthma (14) and respiratory disease $(15,16)$ in short and long term exposure to ambient air pollution. A multi-center study on air pollution and mortality in Spain by Ballester claimed that $\mathrm{SO}_{2}$ concentrations higher than daily average were related to mortality 
(17). An Italian meta-analysis of short-term effects of air pollution reported that an increase of $2.8 \%$ in cardiovascular diseases was observed due to an increase in sulfur dioxide pollutant levels of $10 \mu \mathrm{g} / \mathrm{m}^{3}$ of daily average (18).

In addition, according to a time-stratified casecrossover study conducted by Lin et al. in Hong Kong, $\mathrm{SO}_{2}$ pollutant had a significant association with increasing acute myocardial infarction (AMI) mortality (19). According to the findings of a study conducted in Shiraz, air quality exceeded standards in 85 days and in another study by Gharechahi et al., significant relationship between sulfur dioxide pollutant and hospitalizations due to respiratory diseases in elderly group and $\operatorname{COPD}(\mathrm{P}<0.001)$ $(20,21)$ was indicated. In many cases sulfur compounds are the main causes of damage to materials (22). Although $\mathrm{SO}_{2}$ and other sulfur oxides have been studied, many questions about their impacts on human health have remained unclear.

\section{Objectives}

Our study aimed to estimate excess hospitalization cases due to chronic obstructive pulmonary disease and acute myocardial infarction disease as a result of shortterm exposure to $\mathrm{SO}_{2}$ during years 2011 and 2012 in six major cities of Iran.

\section{Methods}

This study was conducted in six major cities of Iran. We used the AirQ software to assess and evaluate the health impact of $\mathrm{SO}_{2}$ exposure on human health in six major cities of Iran. Hourly air pollution data related to $\mathrm{SO}_{2}$ were obtained from department of environmental (DOE) of six study cities, from March 2011 to March 2012. Thereafter, 24hour means were calculated. Map and location of studied cities is shown in Figure 1.

Gathered data were in volumetric base but the AirQ software was designed on gravimetric base, so we obtained data of pressure and temperature from Islamic Republic of Iran meteorological organization and used the following equation (22) to convert ppb unit (DOE data) to $\mu \mathrm{g} / \mathrm{m}^{3} \mathrm{unit}$ (model required):

$$
\frac{\mu g}{m^{3}}=\frac{P(m m H g) \times M W \times P P M}{62.4 \times T(K)} \times 1000
$$

Where, MW is molecular weight of pollutant, T is temperature as Kelvin degree and $\mathrm{P}$ is pressure (22). To quantify the health impact due to exposure to $\mathrm{SO}_{2}$, annual mean, winter and summer mean, annual 98 percentile, annual maximum and winter and summer maximum were calculated in all cities and their stations.
All of these corrections, processing and required statistical parameters calculation were performed using microsoft office excel spread sheet. We calculated hospital admission due to acute myocardial infarction and chronic obstructive pulmonary disease (COPD) attributed to $\mathrm{SO}_{2}$ by AirQ2.2.3 tool.

The air quality health impact assessment tool (AirQ) was proposed by the world health organization (WHO) in 2004 and developed by the WHO European centre for environment health, Bilthoven division $(23,24)$. This tool is based on epidemiological studies and statistical equations. Four-screen input of this model are AirQ user screen, location screen, air quality data and parameter screen (25). Outputs of model, present results in tables and graphs. Estimation is based on the attributable proportion (AP), defined as the fraction of the health outcome in a specific population attributable to exposure to specific pollutant during the period of time in a certain area. Attributable proportion is calculated using the following equation (26);

$A P=S U M\{[R R(c)-1] \times p(c)\} / S U M[R R(c) \times p(c)]$

Where, $\mathrm{p}(\mathrm{c})$ is the population of the city and RR is the relative risk of health endpoints in category " $\mathrm{C}$ " of exposure that is obtained from an epidemiological study and exposure-response functions.

Relative risk (RR) is defined as a ratio of the probability of the event when people exposure to probability of the event when people non-exposed. Rate of health outcome attributable to the exposure (IE) was calculated as follows:

$\mathrm{IE}=\mathrm{I} \times \mathrm{AP}(27)$

Where, I is the baseline frequency of the health outcome in the population under investigation. Number of cases attributable to the exposure to pollutant (NE) with known size of population $(\mathrm{N})$ can be calculated as follows:

$\mathrm{NE}=\mathrm{IE} \times \mathrm{N}(27)$

Baseline incidence (BI) is multiplied at population size and attributable proportion (AP) then divided by $10^{5}$ to obtain number of excess cases (28):

$$
\begin{aligned}
& \left(\frac{\text { Baseline incidence } \times \text { Population }}{10^{5}}\right) \\
& \times \text { Attributable proportion }=\text { No.of excess cases }
\end{aligned}
$$

Finally, after importing prepared data to the AirQ tool, results were presented as the excess cases of hospital admission attributed to sulfur dioxide pollutant in each city (28).

\section{Results}

Table 1 shows some calculated parameters of environmental data required for quantification by the model in six 


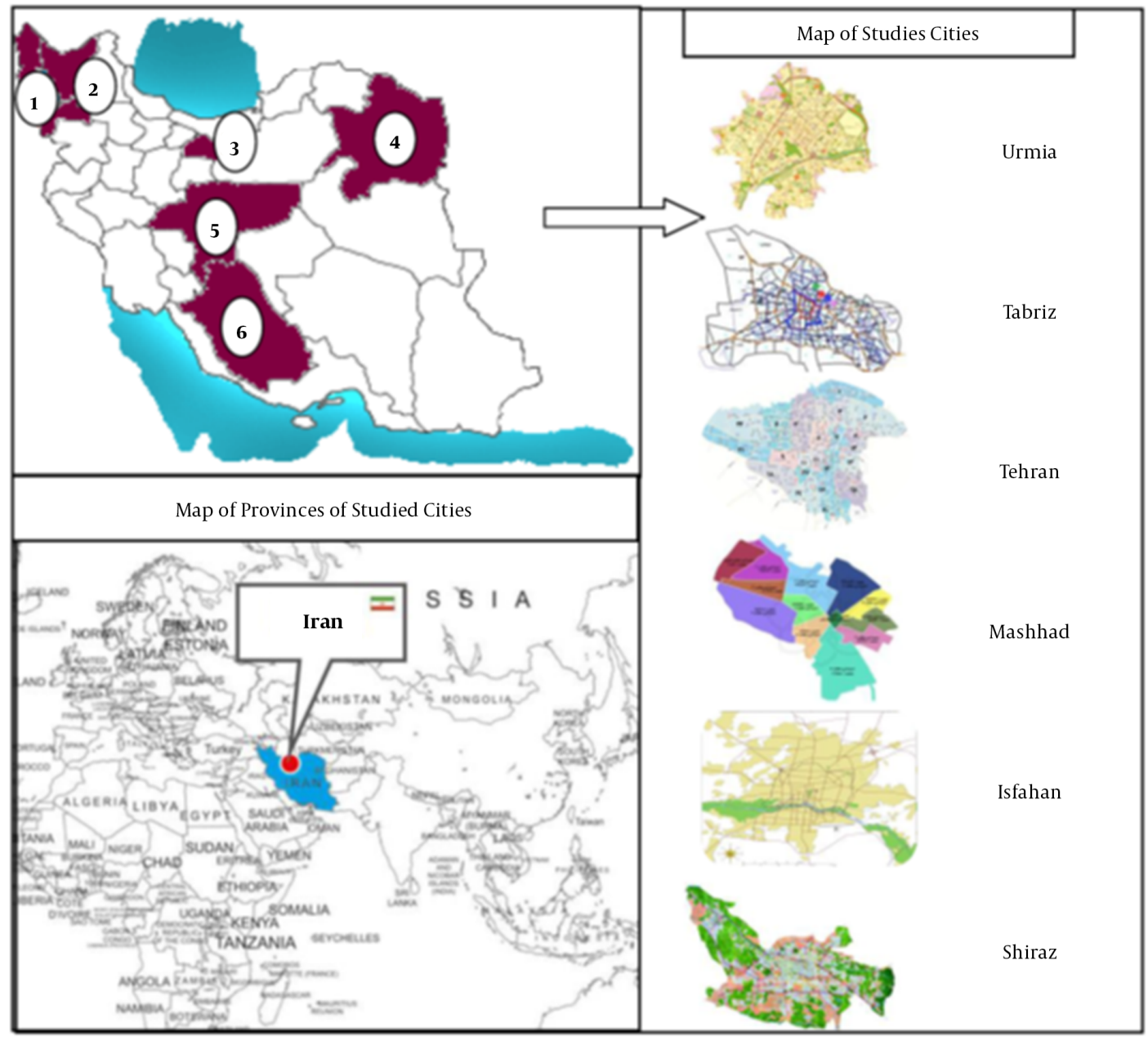

Figure 1. Map of Six Major Cities in Iran and Their Location

cities of Iran. Since $\mathrm{SO}_{2}$ data obtained from DOE were expressed on an hourly basis, we computed daily average values. We applied census data reported by statistical centre of Iran (SCI) in 2010 to determine the exposed population.

As it can be seen in Table 1, highest annual concentrations of sulfur dioxide $\left(\mu \mathrm{g} / \mathrm{m}^{3}\right)$ were recorded in Urmia and Tehran, with mean values of 76 and $49 \mu \mathrm{g} / \mathrm{m}^{3}$, respectively. Overall, $20 \mu \mathrm{g} / \mathrm{m}^{3}$ was determined based on the Iranian national standards as annual average of $\mathrm{SO}_{2}$. According to these standards, in all of the studied cities except Shiraz and Isfahan $\mathrm{SO}_{2}$ exceeded the national standards. During the study period, annual mean concentrations of $\mathrm{SO}_{2}$ in Tabriz and Mashhad were approximately 1.05 and 1.55 times higher than national standards, respectively.

Baseline incidence (BI) and relative risks (RR) with 95\% confidence intervals ( $95 \% \mathrm{CI}$ ) used for the health effect esti- mation in this study are shown in Table 2. Relative risks and $\mathrm{BI}$ used for $\mathrm{SO}_{2}$ based on other studies conducted in Iran and these parameters calculate in Iranian cities (9, 29).

Days (\%) which people in these six cities were exposed to different levels of $\mathrm{SO}_{2}$ are shown in Table 3. In the AirQ, it was assumed that measured concentrations show average exposure of people (30). According to the results, highest percentages of person-day for Urmia, Shiraz, Tabriz, Isfahan, Tehran and Mashhad were $12.5 \%$ (at 30 - $39 \mu \mathrm{g} / \mathrm{m}^{3}$ concentration interval), $49.86 \%$ (at $10-19 \mu \mathrm{g} / \mathrm{m}^{3}$ concentration interval), $47.95 \%$ (at $10-19 \mu \mathrm{g} / \mathrm{m}^{3}$ concentration interval), 21.64 (at $40-49 \mu \mathrm{g} / \mathrm{m}^{3}$ concentration interval) and $31.78 \%$ (at 40 - $49 \mu \mathrm{g} / \mathrm{m}^{3}$ concentration interval), 55.62\% (at $20-29$ $\mu \mathrm{g} / \mathrm{m}^{3}$ concentration interval), respectively (Table 3 ).

Number of excess cases of hospital admissions due to COPD and AMI, as a result of short-term exposure to $\mathrm{SO}_{2}$ 
Table 1. Summary of Required Statistical Parameters, $\mathrm{SO}_{2}$, Annual 24-hour $\left(\mu \mathrm{g} / \mathrm{m}^{3}\right)$ in Six Cities of Iran (2011 - 2012)

\begin{tabular}{|c|c|c|c|c|c|}
\hline Cities & Average & Winter Maximum & Summer Minimum & $\mathbf{9 8} \%$ & Exposed Population \\
\hline Mashhad & 31 & 61 & 41 & 48 & 2750000 \\
\hline Tehran & 49 & 118 & 88 & 94 & 9000000 \\
\hline Isfahan & 12 & 26 & 20 & 19 & 1987000 \\
\hline Tabriz & 21 & 18 & 34 & 66 & 1495000 \\
\hline Shiraz & 11 & 34 & 32 & 25 & 1540000 \\
\hline Urmia & 76 & 176 & 188 & 159 & 680000 \\
\hline
\end{tabular}

Table 2. Baseline Incidence and Relative Risks for Health Endpoints of $\mathrm{SO}_{2}$ in the Study

\begin{tabular}{lcr}
\hline Indicators & HA- COPD, CI 95\% & HA-Acute myocardial infraction, CI 95\% \\
\hline Relative risk (95\% CI) per 10 $\mu \mathrm{g} / \mathrm{m}^{3}$ & $1.0044(1-1.011)$ & $1.0064(1.0026-1.0101)$ \\
Baseline incidence (per 10 ${ }^{5}$ inhabitants) & 101.4 & 132 \\
\hline
\end{tabular}

concentrations above $10 \mu \mathrm{g} / \mathrm{m}^{3}$ in six cities was estimated (Tables 4 and 5).

According to Table 4, maximum number of excess hospital admissions due to COPD in investigated cities is related to Urmia considering the AP and exposed population.

Results indicate that risks of HA-COPD and HA-AMI increase by $0.44 \%$ and $0.64 \%$ with every $10 \mu \mathrm{g} / \mathrm{m}^{3}$ increase in $\mathrm{SO}_{2}$ concentration, respectively. Output results of AirQ are shown by graphs (Figures 2 and 3 ).

Since the number of excess HA-AMI and HA-COPD for Tehran is much higher than other cities we preferred to show this city in a different scale (Figure 4).

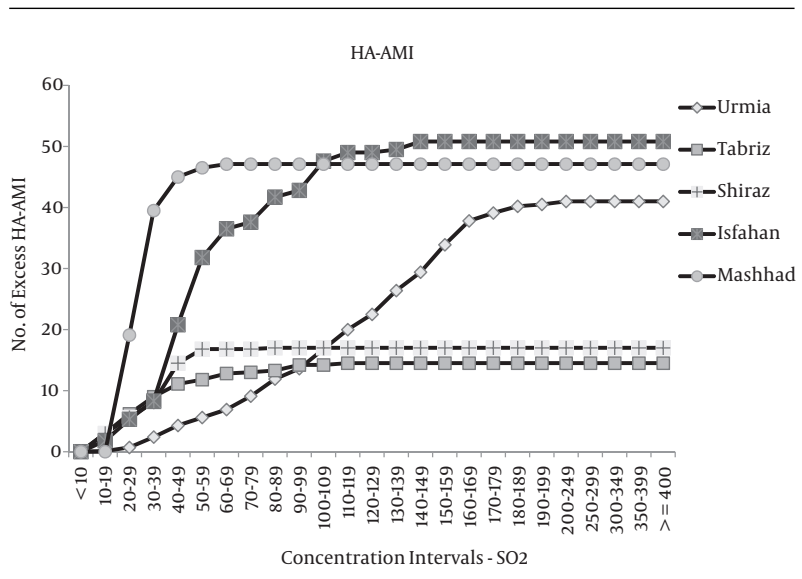

Figure 2. Estimation of Cumulative Number of Hospital Admissions due to Acute Myocardial Infraction Attributable to Sulfur Dioxide Compared to Concentration Intervals by the AirQ Tool in Studied Cities of Iran

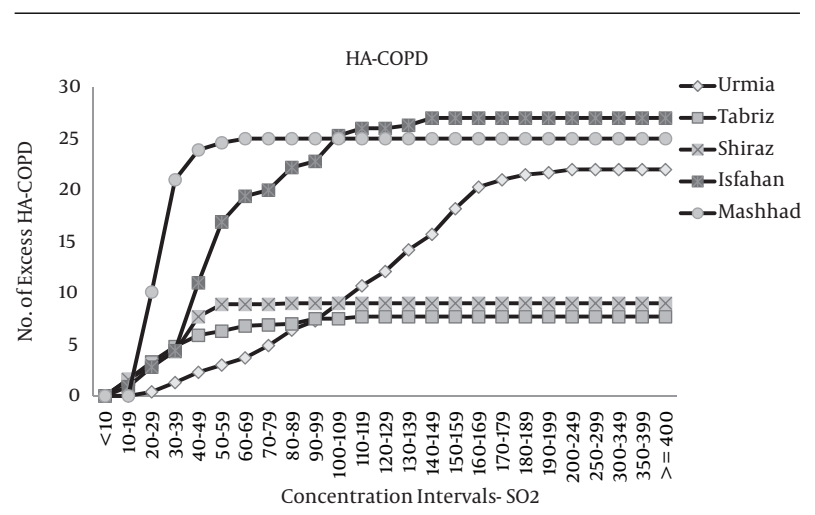

Figure 3. Estimation of Cumulative Number of Hospital Admissions Due to Chronic Obstructive Pulmonary Disease Attributable to Sulfur Dioxide Compared to Concentration Intervals by the AirQ Tool in Studied Cities of Iran

\section{Discussion}

In this study estimation of excess hospitalization due to chronic obstructive pulmonary disease (HA-COPD) and acute myocardial infarction disease (HA-AMI) due to shortterm exposure to SO2 pollutants during years 2011 and 2012 was performed using a model in six major cities of Iran.

According to Table 3, the highest exposure to $\mathrm{SO}_{2}$ in mentioned cities occurred at different concentration levels as follows: $10-19 \mu \mathrm{g} / \mathrm{m}^{3}$ in Shiraz, Isfahan and Tabriz, 20 $-29 \mu \mathrm{g} / \mathrm{m}^{3}$ in Mashhad, $30-39 \mu \mathrm{g} / \mathrm{m}^{3}$ in Urmia and $40-49$ $\mu \mathrm{g} / \mathrm{m}^{3}$ in Tehran. Based on Table 1, annual concentration of $\mathrm{SO}_{2}$ in Tehran, Mashhad, Isfahan, Shiraz, Tabriz and Urmia was $2.45,1.55,0.6,0.55,1.05$ and 3.8 times higher than the WHO standards $\left(20 \mu \mathrm{g} / \mathrm{m}^{3}\right)$, respectively. Therefore, all of the studied cities exceeded the $\mathrm{SO}_{2}$ national standards ex- 
Table 3. Percentage of Days That People in the Six Cities are Exposed to Different Levels of $\mathrm{SO}^{2}$

\begin{tabular}{|c|c|c|c|c|c|c|}
\hline Concentration intervals, $\mu \mathrm{g} / \mathrm{m}^{3}$ & Urmia & Tabriz & Tehran & Shiraz & Isfahan & Mashhad \\
\hline$<\mathbf{1 0}$ & 2.14 & 16.99 & 0.27 & 8.22 & 5.48 & 0 \\
\hline $10-19$ & 2.86 & 47.95 & 4.93 & 49.86 & 21.37 & 0 \\
\hline $20-29$ & 7.5 & 16.99 & 6.3 & 14.25 & 14.25 & 55.62 \\
\hline $30-39$ & 12.5 & 9.04 & 16.44 & 8.22 & 7.4 & 35.62 \\
\hline $40-49$ & 10 & 4.66 & 31.78 & 15.07 & 21.64 & 6.85 \\
\hline $50-59$ & 5 & 1.37 & 20.82 & 4.11 & 14.79 & 1.37 \\
\hline $60-69$ & 4.29 & 1.37 & 9.59 & 0 & 5.21 & 0.55 \\
\hline $70-79$ & 6.43 & 0.27 & 3.84 & 0 & 1.1 & 0 \\
\hline $80-89$ & 6.79 & 0.27 & 2.47 & 0.27 & 3.29 & 0 \\
\hline 90 - 99 & 3.57 & 0.82 & 2.47 & 0 & 0.82 & 0 \\
\hline $100-109$ & 6.07 & 0 & 0.55 & 0 & 3.01 & 0 \\
\hline $110-119$ & 5.71 & 0.27 & 0.55 & 0 & 0.82 & 0 \\
\hline $120-129$ & 3.93 & 0 & 0 & 0 & 0 & 0 \\
\hline $130-139$ & 5.71 & 0 & 0 & 0 & 0.27 & 0 \\
\hline 140 - 149 & 3.93 & 0 & 0 & 0 & 0.55 & 0 \\
\hline 150 - 159 & 5.71 & 0 & 0 & 0 & 0 & 0 \\
\hline $160-169$ & 4.64 & 0 & 0 & 0 & 0 & 0 \\
\hline 170 - 179 & 1.43 & 0 & 0 & 0 & 0 & 0 \\
\hline 180 - 189 & 1.07 & 0 & 0 & 0 & 0 & 0 \\
\hline $190-199$ & 0.36 & 0 & 0 & 0 & 0 & 0 \\
\hline $200-249$ & 0.36 & 0 & 0 & 0 & 0 & 0 \\
\hline $250-299$ & 0 & 0 & 0 & 0 & 0 & 0 \\
\hline $300-349$ & 0 & 0 & 0 & 0 & 0 & 0 \\
\hline $350-399$ & 0 & 0 & 0 & 0 & 0 & 0 \\
\hline$\geq 400$ & 0 & 0 & 0 & 0 & 0 & 0 \\
\hline
\end{tabular}

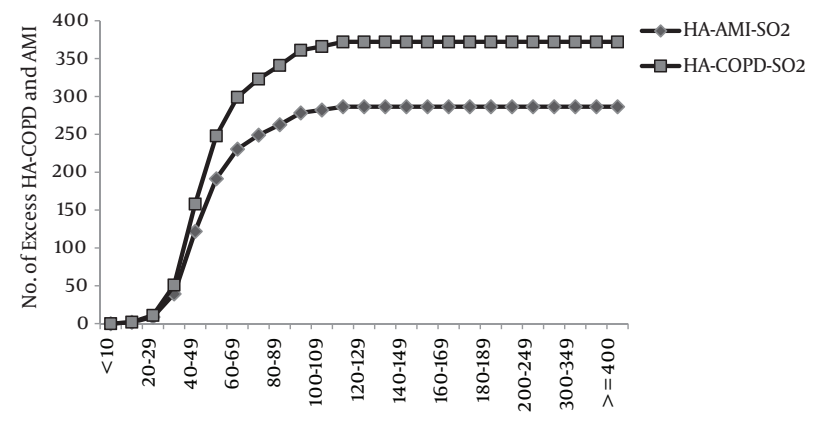

Concentration Intervals- $\mathrm{SO} 2$

Figure 4. Estimation of Cumulative Number of Hospital Admissions Due to Chronic Obstructive Pulmonary Disease Attributable to Sulfur Dioxide Compared to Concentration Intervals by the AirQ tool in Tehran cept Shiraz and Isfahan.

The total cumulative number of hospital admissions due to COPD (HA-COPD) was estimated in six Iranian major cities, which was 243 cases in central relative risk in a year. For hospital admission due to acute myocardial infraction (AMI), the highest impact of $\mathrm{SO}_{2}$ exposure was for Urmia with attributable proportion (AP) of $4.56 \%$, corresponding to 41 excess cases in this city. Overall, 225 AMI hospital admission cases attributed to $\mathrm{SO}_{2}$ were reported in Tehran city by Kermani et al. (2014) (31).

In a study conducted in Korea (from January 2011 to December 2011), number of excess cases of HA COPD and HA AMI was 32.1 and 6 in central RR, respectively (26). In our study total number of excess hospitalization cases due to COPD and AMI as a result of short-term exposure to $\mathrm{SO}_{2}$ was 690 in all studied cities. Geravandi et al. (2015) studied the incidence of health endpoint in Ahvaz and recorded 173 
Table 4. Number of Hospital Admissions due to Chronic Obstructive Pulmonary Disease (COPD)

\begin{tabular}{|c|c|c|c|c|}
\hline Health End Point (Hospitalization) & City & $\mathbf{R R}$ & AP & $\begin{array}{c}\text { No. of Excess Cases, Uncertainty } \\
\text { Range }\end{array}$ \\
\hline \multirow{18}{*}{$\begin{array}{l}\text { Hospital admission due to chronic obstructive pulmonary } \\
\text { (HA-COPD ) }\end{array}$} & \multirow{3}{*}{ Mashhad } & Central & 0.89 & 25 \\
\hline & & Lower & 0 & 0 \\
\hline & & Upper & 2.21 & 62 \\
\hline & \multirow{3}{*}{ Tehran } & Central & 1.67 & 152 \\
\hline & & Lower & 0 & 0 \\
\hline & & Upper & 4.07 & 371.7 \\
\hline & \multirow{3}{*}{ Shiraz } & Central & 0.61 & 9 \\
\hline & & Lower & 0 & 0 \\
\hline & & Upper & 1.51 & 22 \\
\hline & \multirow{3}{*}{ Isfahan } & Central & 1.33 & 27 \\
\hline & & Lower & 0 & 0 \\
\hline & & Upper & 3.28 & 66 \\
\hline & \multirow{3}{*}{ Tabriz } & Central & 0.5 & 8 \\
\hline & & Lower & 0 & 0 \\
\hline & & Upper & 1.25 & 19 \\
\hline & \multirow{3}{*}{ Urmia } & Central & 3.18 & 22 \\
\hline & & Lower & 0 & 0 \\
\hline & & Upper & 7.59 & 52 \\
\hline
\end{tabular}

Abbreviations: AP, Attributable Proportion; RP, Relative Risk.

Table 5. Estimated Attributable Proportion (AP) Expressed as Percentages and Number of Excess Cases in a Year Due to Short-Term Exposure Above $10 \mu \mathrm{g} / \mathrm{m}^{3}$ for SO ${ }_{2}$

\begin{tabular}{|c|c|c|c|}
\hline Health End Point, Hospitalization & & AP, Attributable Proportion & No. of Excess Cases, Uncertainty Range \\
\hline \multirow{6}{*}{ HA-Acute myocardial infraction } & Mashhad & $1.29(0.53-2.03)$ & $47(19-74)$ \\
\hline & Tehran & $2.41(0.99-3.75)$ & $286(118-446)$ \\
\hline & Shiraz & $0.89(0.39-1.39)$ & $17(7-27)$ \\
\hline & Isfahan & $1.93(0.79-3.02)$ & $51(21-79)$ \\
\hline & Tabriz & $0.73(0.3-1.15)$ & $15(6-23)$ \\
\hline & Urmia & $4.56(1.9-7.01)$ & $41(17-63)$ \\
\hline
\end{tabular}

$\mu \mathrm{g} / \mathrm{m}^{3}$ for maximum annual concentration of $\mathrm{SO}_{2}$, which was observed during winter of 2012. Their study also reported that about $5.6 \%$ of COPD cases attributed to $\mathrm{SO}_{2}$ occurred at higher than $20 \mu \mathrm{g} / \mathrm{m}^{3}$ concentrations (26). In another study in Ahvaz (2014), the number of myocardial infarction and cardiovascular death cases associated with sulfur dioxide exposure was estimated to be 37 and 165, respectively (32).

Results implied that sulfur dioxide with highest and lowest AP was reported in Urmia and Tabriz, respectively, indicating the highest and lowest health end points (hos- pitalizations). The status of $\mathrm{SO}_{2}$ is more critical in Urmia and Tehran compared with other areas.

In a study conducted in six cities of Harvard, increased death rates in cities were reported with higher $\mathrm{SO}_{2}$ levels (33). Overall, studies carried out on this issue showed convincing evidences on the role of pollutants in the incidence of disease and death. Some other studies have shown that pollutants are a growing concern for public health (34).

Despite the fact that there is positive and direct relationship between sulfur dioxide and the total daily number of mortality, ranges of impacts attributable to expo- 
sure to $\mathrm{SO}_{2}$ or a mixture of pollutants are yet unclear. According to Dennison et al. (2002), since there are correlations between $\mathrm{SO}_{2}$ and other pollutants in the air, attributing the observed effects just to SO2 is difficult (35).

Although relative risk per $10 \mu \mathrm{g} / \mathrm{m}^{3}$ is low and sometimes mortality and morbidity attributable to pollutant seems slight because of sensitive and large population exposed to air pollutants, burden of disease associated with air pollution will be great. Sulfur compounds are the main cause of damage to materials in many cases (22). Although $\mathrm{SO}_{2}$ and other sulfur oxides have been studied, many questions about their impacts on human health have remained unanswered.

Some possible measures proposed to reduce sulfur dioxide emissions are as follows: use of low-sulfur heavy fuel oils, diminution in coal consumption, reducing the sulfur content of fuels and desulphurization of flue gas, etc. Thus, authorities should apply necessary actions and efforts based on comprehensive scientific researches in order to control air pollutants and abate their negative effects on human health. Adopting effective methods to improve air quality and to reduce people's exposure to air pollution can be considered by policy makers.

\section{Acknowledgments}

This work was funded by Iran University of Medical Sciences, Grant number 24221. We also thank environmental protection agency of all studied major cities for providing us pollutants concentration data. We acknowledge the critical comments from anonymous reviewers and editors.

\section{Footnote}

Authors' Contribution: Study concept and design, Majid Kermani; acquisition of data, Sima Karimzadeh and Farshad Bahrami Asl; analysis and interpretation of data, Mina Aghaei, Sevda Fallah Jokandan and Mohsen Dowlati; drafting of the manuscript, Mina Aghaei; critical revision of the manuscript for important intellectual content, Majid Kermani.

\section{References}

1. Kampa M, Castanas E. Human health effects of air pollution. Environ Pollut. 2008;151(2):362-7. doi: 10.1016/j.envpol.2007.06.012. [PubMed: 17646040].

2. Kermani M, Bahrami Asl F, Aghaei M, Arfaeinia H, Karimzadeh S, Shahsavani A. Comparative investigation of air quality index (aqi) for six industrial cities of iran. Urmia Med J. 2014;25(9):810-19.

3. NEP . Review of the Practicability of a 10 Minute Sulfur Dioxide Standard, Issues Paper. Canberra: National Environment Protection; 2004.
4. Patocka J, Kuca K. Irritant compounds: respiratory irritant gases. Milit Med Sci Lett. 2014;83(2):73-82.

5. Rahila R, Siddiqui M. Review on effects of particulates; sulfur dioxide and nitrogen dioxide on human health. International Res J Environ Sci. 2014;3(4):70-3.

6. Yun Y, Gao R, Yue H, Li G, Zhu N, Sang N. Synergistic effects of particulate matter (PM 10) and SO2 on human non-small cell lung cancer A549 via ROS-mediated NF- $\kappa$ B activation. J Enviro Sci. 2015;31:146-53.

7. WHO . Sulfur dioxide, Air Quality Guidelines, Chapter 7.4.2 ed. Copenhagen, Denmark: WHO Regional Office for Europe; 2000.

8. Colls J. Air Pollution London. 2 ed. ; 2002.

9. Commission of the European communities, Brussels, 2005 Sept 21. SEC (2005) 1133. ; .

10. Le Tertre A, Quenel P, Eilstein D, Medina S, Prouvost H, Pascal L, et al. Short-term effects of air pollution on mortality in nine French cities: a quantitative summary. Arch Environ Health. 2002;57(4):311-9. doi: 10.1080/00039890209601414. [PubMed:12530597].

11. Gouveia N, Fletcher T. Time series analysis of air pollution and mortality: effects by cause, age and socioeconomic status.JEpidemiol Community Health. 2000;54(10):750-5. [PubMed: 10990478].

12. Koken PJ, Piver WT, Ye F, Elixhauser A, Olsen LM, Portier CJ. Temperature, air pollution, and hospitalization for cardiovascular diseases among elderly people in Denver. Environ Health Perspect. 2003;111(10):1312-7. [PubMed: 12896852].

13. Sunyer J, Ballester F, Tertre AL, Atkinson R, Ayres JG, Forastiere F, et al. The association of daily sulfur dioxide air pollution levels with hospital admissions for cardiovascular diseases in Europe (The Aphea-II study). Eur Heart J. 2003;24(8):752-60. [PubMed: 12713769].

14. Andersson E, Knutsson A, Hagberg S, Nilsson T, Karlsson B, Alfredsson $\mathrm{L}$, et al. Incidence of asthma among workers exposed to sulphur dioxide and other irritant gases. Eur Respir J. 2006;27(4):720-5. doi: 10.1183/09031936.06.00034305. [PubMed: 16585079].

15. Martins LC, Latorre Mdo R, Saldiva PH, Braga AL. Air pollution and emergency room visits due to chronic lower respiratory diseases in the elderly: an ecological time-series study in Sao Paulo, Brazil. J Occup Environ Med. 2002;44(7):622-7. [PubMed: 12134525].

16. Sunyer J, Atkinson R, Ballester F, Le Tertre A, Ayres JG, Forastiere F, et al. Respiratory effects of sulphur dioxide: a hierarchical multicity analysis in the APHEA 2 study. Occup Environ Med. 2003;60(8):2. [PubMed: 12883029].

17. Ballester F, Saez M, Perez-Hoyos S, Iniguez C, Gandarillas A, Tobias A, et al. The EMECAM project: a multicentre study on air pollution and mortality in Spain: combined results for particulates and for sulfur dioxide. Occup Environ Med. 2002;59(5):300-8. [PubMed: 11983845].

18. Biggeri A, Bellini P, Terracini B. [Meta-analysis of the Italian studies on short-term effects of air pollution]. Epidemiol Prev. 2001;25(2 Suppl):171. [PubMed: 11515188].

19. Lin H, An Q, Luo C, Pun VC, Chan CS, Tian L. Gaseous air pollution and acute myocardial infarction mortality in Hong Kong: A timestratified case-crossover study. Atmospheric Enviro. 2013;76:68-73. doi: 10.1016/j.atmosenv.2012.08.043.

20. Arfaeinia H, Kermani M, Aghaei M, Bahrami Asl F, Karimzadeh S. Comparative Investigation of Health Quality of Air in Tehran, Isfahan and Shiraz Metropolises in 2011 - 2012. J Health in the Field. 2014;1(4):37-44.

21. Gharehchahi E, Mahvi AH, Amini H, Nabizadeh R, Akhlaghi AA, Shamsipour M, et al. Health impact assessment of air pollution in Shiraz, Iran: a two-part study. J Environ Health Sci Eng. 2013;11(1):11. doi: 10.1186/2052-336X-11-11. [PubMed: 24499576].

22. Wark K, Warner CF, Wayne TD. Air Pollution: It's Origin and Control. 3 ed. ;1999.

23. WHO . Expert Meeting: Methods and tools for assessing the health risks of air pollution at local, national and international level. Geneva: World Health Organization (WHO), Office for Europe; 2014. 
24. Zallaghi E, Geravandi, Nourzadeh Haddad M, Goudarzi G, Valipour L, Salmanzadeh S, et al. Estimation of Health Effects Attributed to Nitrogen Dioxide Exposure Using the AirQ Model in Tabriz City, Iran. Health Scope. 2015;4(4) doi:10.17795/jhealthscope-30164.

25. Kermani M, Gholami M, Aghaei M, Bahrami-Asl F, Shahsavani A, Karimzadeh S. Quantification of Mortality and Hospital Admission Due to Cardiovascular and Respiratory Disease Attributed to PM10 in 7 Metropolitans of Iran during 2011-2012 [ In Persian ].J Health Syst Res. 2016;12(2).

26. Geravandi S, Goudarzi G, Mohammadi MJ, Taghavirad SS, Salmanzadeh S. Sulfur and Nitrogen Dioxide Exposure and the Incidence of Health Endpoints in Ahvaz, Iran. Health Scope. 2015;4(2) doi: 10.17795/jhealthscope-24318.

27. Mohammadi A, Azhdarpoor A, Shahsavani A, Tabatabaee H. Health Impacts of Exposure to PM10 on Inhabitants of Shiraz, Iran. Health Scope. 2015;4(4):31015. doi: 10.17795/jhealthscope-31015.

28. Bahrami Asl F, Kermani M, Aghaei M, Karimzadeh S, Salahshour Arian S, Shahsavani A, et al. Estimation of Diseases and Mortality Attributed to NO2 pollutant in five metropolises of Iran using AirQ model in 20112012. J Mazandaran Univ Med Sci. 2015;25(121):239-49.

29. Kermani M, Bahrami asl F, Aghaei M, Karimzadeh S, Arfaeinia H, Godarzi G. Quantification of Health Effects Attributed to Ozone in Five Metropolises of Iran Using AirQ Model.J Health. 2015;6(3):266-80.

30. Fattore E, Paiano V, Borgini A, Tittarelli A, Bertoldi M, Crosignani P, et al. Human health risk in relation to air quality in two municipalities in an industrialized area of Northern Italy. Environ Res. 2011;111(8):13217. doi: 10.1016/j.envres.2011.06.012. [PubMed: 21764052].

31. Kermani M, Dowlati M, Jafari Jonidi A, Rezaei Kalantari R. Estimation of Mortality, Acute Myocardial Infarction and Chronic Obstructive Pulmonary Disease due to Exposure to O3, NO2, and SO2 in Ambient Air in Tehran. J Mazandaran Univ Med Sci. ;26(138):96-107.

32. Goudarzi GH, Geravandi S, Salmanzadeh S. javad Mohammadi M, Zallaghi E. The number of myocardial infarction and cardiovascular death cases associated with sulfur dioxide exposure in ahvaz, iran Arch Hyg Sci. 2014;3(3):112-9.

33. Dockery DW, Pope CA, Xu X, Spengler JD, Ware JH, Fay ME, et al. An association between air pollution and mortality in six U.S. cities. $N$ Engl J Med. 1993;329(24):1753-9. doi: 10.1056/NEJM199312093292401. [PubMed: 8179653].

34. Soleimani Z, Parhizgari N, Dehdari Rad H, Akhoond MR, Kermani M, Marzouni Bagherian M, et al. Normal and dusty days comparison of culturable indoor airborne bacteria in Ahvaz, Iran. Aerobiologia. 2014;31(2):127-41. doi: 10.1007/s10453-014-9352-4.

35. Dennison L, Rolfe K, Graham B. Review of the Ambient Air Quality Guidelines - Health effects of five common air contaminants and recommended protective ranges. Ministry for the Environment Technical report no.12. 2000(13). 